\title{
A moabita e a metáfora do "outro": Rute como modelo cultural de solidariedade
}

\section{The Moabitess and the metaphor of the "other": Ruth as a cultural model of solidarity}

\section{La moabita y la metáfora del "otro": Rut como modelo cultural de solidaridad}

\author{
Elizangela A. Soares ${ }^{*}$
}

\begin{abstract}
RESUMO
Este artigo se ancora na interpretação do livro de Rute como um escrito do período pós-exílico da história de Israel, cujo conteúdo, de caráter ficcional, aborda o problema dos estrangeiros na comunidade de Iahweh, polemizando, sobretudo, contra a política sociorreligiosa de Esdras e Neemias no que se refere às esposas estrangeiras. À diferença de outras composições do mesmo contexto que compartilham características semelhantes, tecnicamente Rute não se trata de uma novela, mas de um conto que constrói uma crítica programática ao modelo de um nacionalismo exclusivista e purista proposto pela elite da golah. Com essa interpretação no horizonte, o texto que se segue oferece uma análise literária do conto e propõe uma leitura de Rute como metáfora do outro e modelo cultural de solidariedade na relação com o estrangeiro.

Palavras-chave: Rute; estrangeiro/imigrante; identidade; solidariedade; ficção legal.
\end{abstract}

\begin{abstract}
This article is based upon the interpretation of the book of Ruth as a writing from the post-exilic period in Israel's history, whose fictional content addresses the problem of foreigners in the community of Yahweh, polemizing especially against Esdras and Nehemiah socioreligious politics regarding foreign wives. Unlike other compositions from the same context sharing similar features, technically Ruth is not a novel; it is a short story that builds a programmatic criticism of the exclusivist and purist model of nationalism proposed by the golab elite. Bearing this in mind, the following text offers a literary analysis of Ruth and proposes a reading of it as a metaphor of the other and a cultural model of solidarity in the relationship with the foreigner.

Keywords: Ruth; foreigner/immigrant; identity; solidarity; legal fiction.

\section{RESUMEN}

Este artículo se basea en la interpretación del libro de Rut como un escrito del período post-exílico de la historia de Israel, cuyo contenido, de carácter ficcional, aborda el problema de los extranjeros en la comunidad de Yahvé, polemizando, sobre todo, contra la política sociorreligiosa de Esdras y Nehemías con respecto a las esposas extranjeras. A la diferencia de otras composiciones del mismo contexto que comparten características similares, técnicamente Rut no se trata de una novela, sino de un cuento que construye una crítica
\end{abstract}

\footnotetext{
* Teóloga, mestra e doutoranda em Ciências da Religião pela Universidade Metodista de São Paulo (UMESP). Docente da Escola de Teologia da Universidade Metodista de São Paulo. E-mail: elizangela. soares@metodista.br.
} 
programática al modelo de un nacionalismo exclusivista y purista propuesto por la elite del golah. Teniendo esto em cuenta, el texto que sigue ofrece un análisis literario del cuento y propone una lectura de Rut como metáfora del otro y modelo cultural de solidaridad en la relación con el extranjero.

Palabras clave: Rut; extranjero/inmigrante; identidad; solidaridad; ficción legal.

\section{Proêmio}

A comida atinge tudo e é o alicerce de toda economia, marcando diferenças sociais, limites, laços e contradições - uma representação de relações de gênero, família e comunidade que evolui infinitamente (COUNIHAN; ESTERIK, 2013, p. 3).

\section{I}

A comida, ao mesmo tempo em que é uma poderosa portadora de construções culturais de identidade e de comunidade, é também o lugar de uma profunda vulnerabilidade. Não havia mais comida no lugar. E a falta de comida é daquelas coisas que desafiam a relação da pessoa com o lugar e com o que ele representa: a afetividade, a pertença, a comunidade, a propriedade, a identidade. Tudo. Sem comida, todas as outras coisas se tornam secundárias. A escassez machuca o espírito e força decisões, desenha movimentos, mesmo na direção daquilo que até então se poderia julgar com desprezo, repulsa até.

É o tema da comida que abre o pequeno livro de Rute. ${ }^{1}$ Conta a narrativa que Belém de Judá atravessava um período de fome. Para escapar desse destino, um chefe de família chamado Elimeleque, sua esposa Noemi e os filhos Malon e Kilion partem de Belém rumo a Moab, do outro lado do mar. Ali a família se estabelece e a vida segue o seu curso. Algum tempo depois, Elimeleque falece. Sem ele, Noemi e os filhos permanecem nos campos de Moab. Malon e Kilion se casam com mulheres moabitas - Orfa e Rute eram os seus nomes. Passados cerca de dez anos, Malon e Kilion também vêm a falecer, e as três mulheres ficam viúvas e sem filhos.

Ao saber que a fome em Belém havia chegado ao fim, Noemi decide voltar para casa. De início, suas noras moabitas a acompanham, mas, em dado momento, ela lhes diz que voltem para a casa materna, em Moab. Elas se recusam. Noemi insiste. Orfa, chorando, concorda em regressar a Moab; Rute permanece. Quando Noemi insiste outra vez no assunto, Rute oferece uma das mais belas peças discursivas de todo o Primeiro Testamento:

Não insista para que te abandone e me afaste de ti; porque para onde fores, irei; e onde passares a noite, eu a passarei; teu povo será meu povo e teu deus, meu deus; onde morreres, morrerei e lá serei sepultada. Que o Senhor me faça o pior se não for a morte que nos separe! (1.16-17 TEB).

Todas as citações bíblicas terão por fonte a BÍBLIA TRADUÇÃO ECUMÊNICA, 1995. 
Vencida, Noemi fica em silêncio e não protesta mais sobre a permanência de Rute.

\section{II}

Em Belém, Noemi é recebida pelas mulheres do lugar. Ela já não é a mesma que havia partido tantos anos antes. Ao lhes contar seus infortúnios, afirma não querer mais ser chamada de Noemi ("agradável”), mas de Mara ("amarga"): a culpa de tudo é do Todo-Poderoso, ressente-se ela.

$\mathrm{Na}$ sequência dos dias, sogra e nora dividem a residência. Rute sustenta a ambas colhendo as sobras deixadas no campo de um homem chamado Boaz, que mais tarde acaba se revelando um parente de Noemi. Ao tomar conhecimento da relação singular de Rute com sua sogra, Boaz permite que ela continue no seu campo e lhe dá grãos extras quando ela volta para casa.

Ao saber de quem se tratava o dono do campo em que a nora esteve recolhendo grãos, Noemi traça um plano para elas pudessem obter proteção mais garantida do que aquela prevista na lei para o pobre. Seguindo as orientações de Noemi, uma noite Rute procura Boaz na eira e apela para que ele estenda sua proteção a ela por meio do casamento, resgatando também a terra deixada a Noemi pelo falecido Elimeleque. Boaz lhe conta da existência de outro parente, mais próximo, que tem direito ou obrigação prioritários sobre a terra, mas promete fazer o que puder por ela. Na manhã seguinte, ele vai ao encontro do outro parente e convoca uma reunião dos anciãos da cidade para resolver o assunto da terra que foi de Elimeleque. O interesse desse outro parente em resgatar a terra esvaece quando Boaz acrescenta o casamento com Rute à equação. Sabendo que se os dois tivessem um filho este poderia reivindicar a terra resgatada como herança, o parente mais próximo abdica do seu direito/obrigação em benefício de Boaz.

Como desfecho da história, Boaz e Rute se casam e têm um filho, que é entregue aos cuidados de Noemi. As mulheres da comunidade festejam e proclamam a criança como filho e protetor de Noemi na sua velhice. Elas também elogiam Rute, dizendo que ela tem mais valor para Noemi do que teriam sete filhos, e dão à criança o nome de Obed. Como esperado, a moabita que nomeia o livro e que está em silêncio desde a cena da eira não está contemplada na genealogia patrilinear que fecha o livro, encerrada com Davi, que mais tarde será rei em Israel.

\section{III}

Entre as leituras possíveis, o livro de Rute conta a história de duas mulheres desoladas pelas consequências práticas da perda. A narrativa é fixada 
em um passado distante, no período em que Israel havia sido governado pelos Juízes, por volta de 1100 aEC, e seu caráter ficcional transparece já na sentença de abertura: "Certa vez, no tempo dos Juízes..." (1.1). Ao lê-la, tem-se quase uma sensação de "era uma vez".

A despeito da ambientação ficcional, a datação da obra, no entanto, experimenta hipóteses que vão da época pré-exílica a uma data tardia, no pós-exílio ${ }^{2}$. Defensores de uma data pós-exílica localizam a escrita de Rute entre 350 e 450 aEC, após a volta para Jerusalém dos exilados na Babilônia, no contexto do desenvolvimento de um forte espírito nacionalista nutrido pela promulgação de uma série de leis que objetivavam manter a pureza judaica, com implicações especiais para as relações com estrangeiros (veja Ed 9; 10 e Ne 13.1-3, 23-31). Considerando esse contexto e à vista do tema discutido na obra, essa segunda hipótese de datação nos parece a mais plausível.

A autoria de Rute é desconhecida, embora alguns comentaristas especulem uma sensibilidade autoral feminina, levando em conta o primeiro plano incomum assumido pelas mulheres na história. Expressões como "marido de Noemi" (1.3) e "casa materna" (1.8) em vez dos tradicionais e esperados "mulher de Elimeleque" e "casa paterna" funcionariam como indícios nessa teoria de uma autoria feminina (GOITEN, 1988; LEFKOWITZ, 1991; KRAEMER, 1991; BLEDSTEIN, 2001; FISCHER, 2006). Quer de autor, quer de autora, a pequena obra exibe sofisticação literária e familiaridade com o conteúdo e o estilo das narrativas ancestrais do Gênesis (por exemplo, 12.1; 19; 38), bem como as tradições do deserto em Números (22-24; 25), estatutos legais sobre os direitos dos pobres (Dt 24.19-21), a exclusão dos moabitas pelos israelitas (Dt 23.4-5), casamento exogâmico (Dt 7.1-3), casamento por levirato (Dt 25.5-10) e o resgate de propriedades (Lv 25.23-25). É, pelo seu próprio mérito, uma peça narrativa notável. De apelo universal, trata-se de uma narrativa sensível, profundamente humana, cujas situações delineadas apresentam largo potencial de identificação. Como obra aberta ${ }^{3}$, convida seus leitores ao jogo dos sentidos e lhes permite recriações, entre elas, Rute como modelo cultural de solidariedade.

\section{O lugar de Rute como narrativa ficcional}

Em "Divã do Oriente e do Ocidente", antologia de poesia lírica de 1819, Goethe fala da Bíblia, mais especificamente do Primeiro Testamento, como a

\footnotetext{
Para uma discussão sobre a datação da obra, veja HUBBARD JR., 1988, p. 23ss.

Veja o conceito de "obra aberta" desenvolvido por Umberto Eco, em que se destaca a perspectiva do leitor/expectador e sua interpretação para o conjunto de significados de uma obra. Cf. ECO, Umberto. Obra aberta. São Paulo: Perspectiva, 2013 (Col. Debates 4).
} 
mais antiga coleção de poesias orientais. Como exemplo cita o livro de Rute, apreciado por ele como "a pequena obra mais bela que nos foi transmitida em forma épica e idílica” (2010, p. 176-177). Desde então, essa despretensiosa descrição de Rute como um idílio passou a figurar nas discussões do gênero literário da obra, ora como parte da definição, ora como objeto de crítica a essas mesmas definições (e.g. GUNKEL, 2014; FEWELL, 2016; FEWELL; GUNN, 2009).

Idílio ou não, no campo dos estudos bíblicos brasileiros, parece haver uma tendência a classificar Rute como uma "novela" (e.g. MESTERS, 1989, p. 13; GONÇALVES, 2008, p. 215; DREHER, M. N., 2013, p. 225; DREHER, C. A., 2012, p. 236; MARIANNO, 2010, p. 117). Mas não nos parece ser o caso. Quando se fala em novelas no mundo antigo ou, mais especificamente, em "novela antiga", tem-se em mente um período, um contexto e um corpus textual de características muito bem definidas. Em termos de período, os cinco primeiros séculos da Era Comum; no que se refere ao contexto, o greco-romano; no que tange ao corpus literário, narrativas inteiramente ficcionais em prosa, longas, de caráter popular, regidas por motivos eróticos, envolvendo uma série de aventuras, geralmente no decurso de uma viagem ${ }^{4}$. Isso, é claro, define as novelas do amor ideal (gregas) ${ }^{5}$ e as cômico-realistas (romanas) ${ }^{6}$. Obras de tipo novelesco, marginais ${ }^{7}$ possuem certas características novelísticas, mas não são derivadas das novelas ideais nem apresentam links associativos constantes com elas que as tornem parte da família chamada "novela antiga".

Pelo menos dois séculos antes de gregos e romanos, no entanto, os judeus já haviam iniciado uma produção de textos ficcionais em prosa, um gênero distinto dentro da literatura judaica antiga, representado pelas narrativas de Ester, Daniel, Tobit, Judite e José e Asenet. O conjunto dessas narrativas, localizado entre 200 aEC e 100 EC, por analogia de objetivo e topoi típicos (amor, aventura, perigo, virtude etc.), é denominado "novela judaica". Trata-se de um corpus caracterizado por "cenários fantasiosos e idealizados, tom aventuresco, finais felizes e personagens femininas fortes" exercendo o protagonismo. Esses escritos provavelmente eram considerados ficcionais, "não no sentido de história inferior ou crédula que deturpa o passado, mas no sentido

\footnotetext{
Veja a definição mais ampla do gênero "novela antiga" oferecida por HOLZBERG, 2005, p. 20.

Quéreas e Calírroe, de Cáriton (4 EC); Efesiacas on Antia e Habrócomes, de Xenofonte de Éfeso (1-2 EC); Dafnis e Cloé, de Longo (2 EC); Leucipe e Clitofonte, de Aquiles Tácio (2 EC); As Etiópicas, de Heliodoro (4 EC).

${ }^{6}$ Satíricon, de Petrônio (1 EC) e o Asno de Ouro ou Metamorfoses, de Apuleio (2 EC).

7 Das Narrativas Verdadeiras, de Luciano (2 EC), a Vida de Apolônio de Tiana, de Filostrato (3 EC), os anônimos Romance de Alexandre, Vida de Esopo, Atos de Paulo e Tecla (2 EC), entre outros.
} 
de escritos em prosa que envolvem um novo tipo de experiência, a criação de mundos inventados que são, todavia, como o nosso" (WILLS, 1995 p. 1).

Lawrence Wills oferece uma definição de novela para o corpus novelístico judaico ${ }^{8}$ como "narrativa de ficção popular escrita, expandida signiffcativamente para além de um único episódio, que se concentra no caráter e na virtude" (2002, p. 5). Ele logo esclarece que o sentido de "popular" empregado em sua definição não está relacionado ao consumo dos textos, mas à sua função principal como ficções de entretenimento - um juízo desafiado por estudiosos menos interessados na pauta literária e mais afeitos à interpretação de que as ficções judaicas são desenhadas para apoiar e favorecer a agenda ideológica do próprio autor, que seria a criação de uma concepção particular da identidade judaica (JOHNSON, 2005, p. 189). Contudo, essas posições não precisam necessariamente representar interpretações concorrentes. Uma leitura disposta dos textos permite observar que, enquanto as ficções do judaísmo antigo carregam um elemento de entretenimento, sua avaliação como meio de reinventar o passado para fortalecer a identidade definitivamente possui um apelo difícil de ser ignorado.

Mas voltemos a Rute. Se a narrativa contém elementos identificáveis como novelísticos (por exemplo, as personagens femininas fortes, o final “feliz"), por que não nos parece uma novela? A razão mais óbvia é que Rute não tem a extensão esperada de uma novela. Segue-se a isso que a obra não dispõe de tantos personagens, sua trama apresenta menos complexidade e seu marco temporal é mais limitado quando comparado a uma novela. Em nossa perspectiva, Rute é mais bem representada pelo gênero da história curta ou conto ${ }^{9}$, ainda que já tenha experimentado designações tão distintas como a já mencionada narrativa idílica, lenda popular, saga, romance e, estranhamente, até comédia (TRIBLE, 1992, p. 842-847, esp. p. 843).

Wills caracteriza Rute como uma narrativa oral, sendo, em virtude disso, muito diferente das novelas judaicas, as quais, embora possam ter se originado como histórias e lendas orais, desenvolveram-se de fato no estágio escrito, influenciadas por novas técnicas literárias (2002, p. 5). Outra diferença fundamental em relação à novela é aquela observada por W. Humphreys, segundo quem "os contos revelam a natureza de um personagem ou de uma

8 Quando falamos em um "corpus novelístico judaico" o fazemos cientes de que essa coletividade é artificial (assim como a ideia geral de cânon), de modo que não está subentendido ou pressuposto que os autores tenham composto suas obras conscientemente iluminados por algum gênero literário, tanto mais um que os pós-date!

9 De gênero popular, segundo E. Campbell, a história curta ou conto foi uma nova forma literária que apareceu em Israel no tempo dos Juízes até o período monárquico. Cf. o estudo completo em CAMPBELL JR., 1974, p. 83-101. Veja também PASCO, 1991, p. 407-422. 
situação, enquanto uma novela desenvolve personagens ou situações” (1985, p. 84-85). Para ele, Rute seria um exemplo de personagem revelado, mas não desenvolvido na narrativa.

Mas nem tudo são diferenças entre conto e novela. Um bom termo de aproximação entre as duas categorias é que uma e outra são ficções que buscam retratar a vida de forma fiel. Fique claro, contudo, que não se trata de descrever o que aconteceu, mas o que acontece na vida. O que o leitor encontra nas novelas e nos contos é a verdade, mesmo que essa verdade não tenha acontecido (HUMPHREYS, 1985, p. 83-84). Nesse aspecto, já havia percebido Wills, "a ficção é um contrato implícito entre autor e leitor, no qual ambas as partes presumem que a narrativa não está tentando recontar eventos reais do passado" (2002, p. 9). Dito de outra maneira, essas ficções narram possibilidades da vida, por isso criam identificações, como no caso de Rute.

\section{Rute, um conto}

I

Rute é um conto sobre pessoas comuns enfrentando seus problemas (o que acontece na vida): como lidar com a escassez de comida; que fazer quando se perde os membros masculinos da família estando em terra estranha; que fazer, sem proteção, na condição de pobre, mulher e imigrante irregular; como usar a lei a seu favor.

O conto tem início com uma espécie de flashback que narra acontecimentos que teriam se passado no curso de dez anos antes da história principal. Esse flashback informa ao leitor que Belém de Judá esteve sofrendo com a escassez de comida. Para escapar da fome, Elimeleque deixa Belém com sua família. Eles partem para Moab, que não compartilhava da triste sorte de Belém. Em Moab, Elimeleque morre, os filhos se casam com mulheres locais e, eventualmente, também morrem: uma situação que, como o texto prefere enfatizar, deixa Noemi sem os dois filhos e sem o marido (1.5) - maneira como a narrativa escolhe indicar o que aguarda uma mulher sem uma figura masculina que a represente na tradição judaica antiga.

Em uma narrativa permeada por elementos controversos, esse flashback introduz logo de início o primeiro deles: além de abandonar sua comunidade em um momento de crise, Elimeleque foi com a família viver na terra dos inimigos históricos dos israelitas! Não bastasse isso, seus filhos se casaram com mulheres moabitas, uma clara infração da proibição do casamento com mulheres estrangeiras. Rute, sem qualquer cerimônia, começa de forma polêmica. 
Noemi se dá a conhecer por meio dos seus discursos (1.8-15, 20-21; 2.2, 19-22; 3.1-4, 16, 18). Ela é uma mulher arguta e consciente do seu papel. Somos expectadores da sua partida com a família para longe de casa em busca de comida; a perda dos entes queridos, atribuída por ela ao castigo e abandono por Deus; o regresso para Belém; sua amargura e reação face às circunstâncias da vida: não me chame de Noemi (agradável, amável), mas de Mara (amarga, um antônimo conveniente); sua relação especial com Rute; sua compreensão da própria condição enquanto mulher sem marido e descendência; o seu plano para superar o caos que havia tomado conta da vida. Seguimos com ela até o nascimento do filho de Rute, que coroa o sucesso de um plano arriscado e representa a segurança da família (4.16) ${ }^{10}$

Noemi é uma sogra que se vê desempenhando a função de sogro — uma das inversões com que o texto de Rute joga sem qualquer problema. Kristin Saxegaard (2010, p. 81) lembra que Gn 38 indica uma tarefa específica relacionada ao sogro: encontrar um novo pretendente para uma nora deixada sem filhos pelo marido falecido. É exatamente essa a tarefa que Noemi assume, embora fosse esperado que a família de Elimeleque o fizesse.

\section{III}

Enquanto isso, Rute, de quem o nome não tem significado certo ${ }^{11}$, é revelada na narrativa como uma mulher corajosa, não afeita a reclamações, trabalhadora e altruísta, podemos dizer. É a típica "mocinha" dos romances, cuja história começa ao se casar com um judeu, filho de um casal de estrangeiros que tentava a sorte em Moab. Porém, antes mesmo de completar a família com filhos, ficou viúva. Nenhuma menção é feita do seu sofrimento pela perda do marido ou do que essa experiência poderia significar para ela pessoal ou socialmente. Do início ao fim do conto, Rute é uma mulher apenas resignada.

O segundo movimento em sua trajetória descreve uma mulher passando à condição de estrangeira, deixando sua pátria para estar com a sogra. Ela

\footnotetext{
10 E por falar em leituras possíveis, Zefira Gitay destaca o protagonismo de Noemi e sua posição sempre superior na narrativa, colocando, a partir dessas constatações, a pergunta: por que, então, o livro leva o nome de Rute e não o de Noemi? Sua hipótese é a de que Noemi não nutria afeição pela nora, cujo casamento com o filho não aprovava e na companhia de quem não tinha prazer. Em nenhum momento da narrativa percebe-se, segundo o seu argumento, uma natureza generosa para as suas ações. "Quem quer que tenha dado o nome de Rute ao manuscrito o leu cuidadosamente; e a escolha do nome implica uma crítica a Noemi”, conclui (cf. GITAY, 2001, p. 186).

11 Veja a discussão sobre o significado do nome e suas ocorrências (em número inferior ao dos demais personagens principais) em SAXEGAARD, 2010, p. 106ss.
} 
não precisava ter feito isso. Como filha de Moab, nenhuma obrigação de obediência à lei judaica estava pressuposta no seu estado de viuvez. Com o marido, o cunhado e o sogro mortos, não havia um casamento por levirato no horizonte, e ela estava livre para voltar para casa. A própria sogra insiste para que ela o faça (1.8).

Estar com a família é estar em segurança, supõe-se. Rute estaria segura com os seus em Moab. Mas, e Noemi? Viúva e sem filhos, ela estaria experimentando a pior tragédia imaginável no contexto do antigo Oriente Próximo: num ambiente em que os homens eram os responsáveis pelo cuidado de suas famílias, Noemi fora deixada sem ninguém que pudesse assumir responsabilidade pelo seu bem-estar. Em um mundo em que as mulheres eram identificadas a partir dos homens (marido ou filhos), ela acabara de perder a sua identidade! Por outro lado, no que se refere à própria Rute, o conto nada nos diz do seu contexto em Moab. Não sabemos no que ela acreditava, o que considerava ou quais eram as condições da "casa materna" para a qual ela se recusou a voltar.

Com a decisão de Rute de permanecer com Noemi, a narrativa permite observar o desenvolvimento de uma relação de cuidado entre nora e sogra, duas mulheres experimentando a vida no seu mais profundo vazio. E com a chegada a Belém no começo da colheita da cevada, temos um fechamento quase poético para o drama até então desenhado. São duas mulheres vulneráveis, pobres e com fome, que passam a depender da bondade de outros para sobreviver.

\section{IV}

Enquanto as duas não tinham nada, para outros havia abundância: os campos estavam prontos para a ceifa, inclusive na área de certo Boaz. Para seu sustento e o de Noemi, ali Rute se viu recolhendo as sobras dos grãos deixadas pelos segadores. Tratava-se de lançar mão do direito do pobre, instituído na Torá como proteção ao órfão, à viúva e ao estrangeiro (Lv 19.9-10; Dt 24.19). Entretanto, moabita, como o argumento retórico do texto faz questão de deixar claro $(1.22 ; 2.2,6,21 ; 4.5,10)$, esse direito não se estendia a ela.

Em The Stranger in God's Land (2014), Hans-Georg Wuench se concentra em distinguir os três termos hebraicos mais empregados para falar sobre a figura do estrangeiro no Primeiro Testamento: zar, nochri e ger. Ele explica que o primeiro termo (zar) tem significado amplo, mais geral e neutro, podendo variar desde o israelita que vive em um local ao qual não pertence até o estrangeiro que vem de outro país. A ênfase está posta na distância. Os outros dois casos, todavia, envolvem certa subjetividade. O estrangeiro 
identificado como nochri evoca alguém potencialmente perigoso, que deveria ser excluído da comunidade social israelita sempre que possível, e que estava fora da comunidade cúltica de Yahweh. Deles os israelitas sequer deveriam comprar animais para sacrifício. Seus deuses e modo de vida eram perigosos, porquanto as diferenças entre eles e o israelita deveriam ser bem delimitadas (e.g. Exx 21.8; Dt 14.21; 15.3; 17.15; 23.21; Pv 5.10; 20.16; 27.13; Ec 6.2). A última categoria (ger) se refere ao estrangeiro residente. Sendo a mais comum no texto hebraico, diz respeito ao imigrante. Estes não são cidadãos plenos, mas estão bem integrados à comunidade, de modo que não são apenas tolerados, mas participam da sua vida política, social e religiosa, gozando de certos direitos e de proteção (e.g. Êx 12.49; Lv 18.26; 24.22; Nm 15.15-16; Dt 29.10; 31.12). Moabita, e de acordo com toda a tradição por detrás do que isso representa, Rute cai na segunda categoria (nochri), o que significa que ela está naquele lugar irregularmente e pode ser expulsa.

Boaz veio da cidade para visitar seus campos. O leitor sabe da sua presença, porém Rute, não. Ela está respigando atrás dos segadores, completamente alheia. Ela não sabia quem era Boaz, mas ele a nota imediatamente e quer saber quem ela é (“A quem pertence esta jovem?” - 2.5 TEB). Ao ser informado de que se trata de uma moabita, seria esperado que ele desse ordens para que ela fosse retirada da sua propriedade, afinal, há que se observar a Torá! O que se passa, entretanto, é o oposto. Quando se encontram, Rute refere a si mesma como nochrah (2.10), mas não é tratada por Boaz como se o fosse. Ele havia reunido algum conhecimento sobre ela antes de se encontrarem pessoalmente (2.5-7). Esse conhecimento o leva a trata-la como ger. A razão para isso, segundo Wuench, é que Rute se comportava como era esperado de um ger:

a responsabilidade para com uma família israelita, a disposição em deixar sua própria família e nação e viver de uma maneira mais ou menos permanente com outro povo. Boaz, portanto, sabia que Rute, na verdade, era uma estrangeira residente (ger), não uma nochrah, e ele a tratou dessa maneira [...]" (WUENCH, 2014, p. 1149).

Impressionado com sua bondade e cuidado para com Noemi, Boaz autoriza que Rute continue respigando em seus campos, que beba da água dos demais trabalhadores, a convida para compartilhar a refeição junto dele e dos segadores e assegura que ela possa recolher e levar para casa mais do que seria necessário (2.15-17). A fome, porém, não era o único perigo à sua espreita; como mulher e estrangeira, ela também estava à mercê da violência sexual. Boaz também cuida desse assunto e garante a sua proteção permitindo que ela trabalhe junto com as outras mulheres, oferecendo-lhe a segurança da 
companhia do grupo, ao mesmo tempo em que orienta os homens a serem gentis com ela e que não a "toquem" (2.8-9).

\section{V}

"O homem no campo de quem trabalhei se chama Boaz" (2.19 TEB), conta Rute à sua sogra no final do dia, trazendo para casa o produto do seu trabalho e entregando-lhe a porção de comida que havia guardado para ela. Feliz coincidência, Rute fica sabendo que o dono daqueles campos, que havia sido tão generoso com ela, era parente de Noemi. Tem início, então, um novo movimento na história da moabita que retrata uma criativa ficcionalização da lei judaica.

Noemi explica a Rute que, como parente próximo, Boaz conserva o direito de resgate. A instituição do resgate de propriedades ( $\mathrm{Lv} 25.23 \mathrm{ss}$ ) tinha como objetivo cuidar para que parentes empobrecidos não fossem totalmente arruinados do ponto de vista econômico e social. O direito de resgate obrigava moralmente que um dos membros da família em dificuldade se apresentasse como "resgatador". No conto de Rute, Noemi surge como candidata à proteção por essa instituição. Mas esse não é o único dispositivo legal de que o conto lança mão. No capítulo 3, Noemi se dá conta de que, com algum engenho e certa criatividade, a lei também poderia beneficiar Rute.

"Minha filha, não devo buscar para ti uma situação em que sejas feliz? Ora, não é nosso parente esse Boaz [...]?" (3.1-2 TEB). Claramente Noemi tem em mente o levirato (Dt 25.5-10), e o texto que se segue descreve o impulso para a sua concretização. O levirato se tratava da garantia do direito sobre a terra àquele que morresse sem ter filhos; isso se dava pela prescrição de que o irmão do falecido gerasse um filho com sua viúva, continuando, desse modo, a linhagem do morto. Note que o beneficiário dessa lei é o homem morto. No entanto, em outra subversiva e brilhante inversão, o levirato em Rute está centrado no interesse das mulheres!

O capítulo 3 revela instruções de uma experimentada Noemi para que Rute seduza Boaz. Essa parte da narrativa tem um ar erótico, com Noemi orientando a nora sobre como se aproximar. Primeiramente, no final do capítulo anterior, ela já havia instruído Rute a continuar trabalhando somente nos campos de Boaz. Agora, seguindo suas direções, a jovem deveria se preparar com banho e perfume, colocar seu manto e descer até a eira. Ali ela deveria permanecer escondida até que Boaz terminasse de comer e de beber. Depois que ele tivesse se deitado, ela descobriria seus pés (provavelmente um circunlóquio para desnudá-lo) e se deitaria perto 
dele $^{12}$. Sem avaliar os riscos implicados no curso dessas ações, Rute faz exatamente conforme a instrução recebida e, no meio da noite, ao acordar, Boaz encontra essa mulher "aos seus pés".

"Sou Rute, tua serva. Desposa tua serva, pois tu és resgatador" (3.9 TEB). Do ponto de vista da tradição judaica, certos limites são violados nesse cenário: estratos sociais (ela é serva/ele é senhor), fronteiras étnicas (ela é moabita/ele é judeu), proibições religiosas (a união com estrangeiros), uma mulher no controle da situação. Nessa perspectiva, com a subversão de estruturas sociais e religiosas rígidas, a narrativa em Rute pode ser vista como um minicarnaval, estabelecendo uma relação dialógica entre as estruturas hegemônicas (representadas por Boaz) e a margem social e religiosa (representada por Rute). ${ }^{13}$

O fato de Boaz surgir como "resgatador" é a justificativa do pedido feito por Rute. Aplicada a escravos e à terra, deve-se ter em mente que a instituição do resgate não está relacionada ao casamento. Esses são domínios completamente diferentes, que em nenhum lugar do Primeiro Testamento se cruzam, exceto por Rute 3.9.

[...] na cena noturna na eira, Rute funde de modo inseparável as duas obrigações de solidariedade familiar, ou seja, o levirato (cf. Deuteronômio 25) e o resgate (cf. Levítico 25), interpretando a lei de Israel de maneira muito criativa a favor das mulheres. Com efeito, as duas mulheres, Rute e Noemi, devem ser mantidas para sempre e inseridas novamente na sociedade. Neste sentido, a instituição do resgate ajuda Noemi porque deve ser adquirido um campo evidentemente ainda à disposição; e a lei do levirato ajuda Rute a integrar-se em Belém (FISCHER, 2016, não paginado).

Como indício da eficácia do plano de Noemi, Boaz promete fazer o que quer que Rute pedisse, desde que o primeiro resgatador (somos informados de que Boaz é o segundo candidato) abrisse mão do seu direito de comprar ("resgatar") de Noemi as terras que eram de Elimeleque. O encontro entre os dois resgatadores potenciais e a transação que eles performam é o tema de mais da metade do quarto e último capítulo do conto. Indagado por Boaz sobre exercer o seu direito de resgate, num primeiro momento o resgatador

12 Para conotações sexuais implicadas em "deitar", bem como na palavra "pé" como eufemismo para pênis, veja BRAULIK, 1999, p. 15; HALTON, 2012, p. 32; LaCOCQUE, 2004, p. 91; VILLIERS, 2017, p. 47. Para uma posição oposta, segundo a qual Rute subverte o ritual original pretendido por Noemi ao chamar Boaz a um compromisso em vez de oferecer-lhe o seu corpo, veja WETTER, 1998, p. 47ss.

13 Carnavalização é um conceito desenvolvido por Mikhail Bakhtin. Derivado da cultura popular, identifica-se profundamente com a sua valorização da dimensão corporal da vida, que tende a ridicularizar, parodiar e subverter as normas e convenções instituídas (cf. BAKHTIN, 2010). Para um estudo provocativo de Rute na perspectiva carnavalesca bakhtiniana, veja ASCHKENASY, 2007, p. 437-453. 
original responde positivamente à sua obrigação: "Eu quero resgatar" (4.4). $\mathrm{Na}$ sequência, porém, ao ser esclarecido por Boaz de que exercer esse direito trazia no pacote um compromisso por levirato, ele repensa a sua decisão: "Não posso resgatar, senão arruinarei o meu patrimônio" (4.6). Sem disposição para garantir a perpetuação do nome de outro sobre o patrimônio, o primeiro resgatador sai de cena e Boaz oficialmente resgata a terra de Noemi e "adquire" Rute como sua noiva, numa cena que parece combinar ação legal e rito religioso (BECKING; WETTER, 2013, p. 265).

Com a situação jurídica envolvendo o resgatador original contornada, o conto caminha para o final "feliz", em especial para Boaz, que além de casar-se com uma jovem mulher, também aumenta a sua propriedade. Juntos eles concebem um filho, cuja genealogia ao final do capítulo informa ser ninguém menos que o avô do rei Davi. A criança, Obed, representa para Noemi não somente a recuperação da identidade que até então estava perdida, mas também o resgatador que reanimará a sua vida e que cuidará dela em sua velhice (4.14-15). "Um filho nasceu para Noemi!" (4.17 TEB) — não para Elimeleque ou para o marido morto de Rute, mas para Noemi! A vida, antes vazia, está novamente plena - graças à moabita, a estrangeira que vale para Noemi mais do que sete filhos (4.15).

\section{Perspectivas finais: Uma vez migrante, sempre migrante?}

I

Rute, na perspectiva desta leitura, é uma história sobre migração e sobre o que isso representa. Como moabita, Rute estava excluída da comunidade judaica pela Torá: "O amonita e o moabita não poderão entrar na assembleia de Iahweh; e mesmo seus descendentes também não poderão entrar na assembleia de Iahweh até a décima geração, para sempre” (Dt 23.4 BJ).

Há um contexto que oferece os elementos com que Rute constrói a narrativa do trânsito entre personagens israelitas e moabitas: o retorno dos descendentes dos exilados na Babilônia (golah) para o seu antigo território, agora chamado de Yehud. Com o desaparecimento do reino de Judá e dos símbolos identitários nacionais (a cidade, o rei e o templo), essas pessoas assumem para si não só a compreensão de serem o "verdadeiro" Israel ${ }^{14}$, uma comunidade à qual somente os descendentes dos exilados pertencem, mas também a tarefa de reconstruir a identidade. Comissionados pela autoridade

14 Em oposição aos demais que viviam na terra, que incluíam descendentes dos que não haviam ido para o exílio e estrangeiros simpáticos ao judaísmo, assim como às colônias judaicas fora dos limites de Yehud. 
persa para governar a província, a elite desse grupo tinha a influência e o poder (político e religioso) necessários para isso, com sua ação culminando na remoção dos elementos estrangeiros, deixando à mostra uma concepção exclusivista de Israel, muito bem representada pela política sociorreligiosa proposta nos livros de Esdras e de Neemias. ${ }^{15}$

$\mathrm{O}$ conto, que pode ser entendido como uma crítica à perspectiva de um nacionalismo excludente, purista e fechado da elite da golah (COOK, 2015; LaCOCQUE, 2004; BRAULIK, 1999; MATTHEWS, 2004), encerra também uma tensão entre identidade e inclusão, assimilação e aceitação. Como apontado anteriormente, nada é contado no texto sobre "Rute como Rute"; ela surge desarraigada em Moab. No entanto, nas entrelinhas da bonita e espontânea afirmação de lealdade a Noemi, ela parece querer ser vista pela sogra não como uma viúva moabita, mas como a viúva de um israelita. Já em Belém, lança mão de estratégias de integração, com trabalho árduo nos campos e o cuidado da sogra, o que lhe rende boa reputação e um tratamento como ger por Boaz. Em que se pese ser chamada o tempo todo de moabita e jamais mencionar o deus de Israel pelo nome, outras saliências das distinções étnicas são atenuadas. Ao mesmo tempo, embora tenha percorrido um longo caminho desde que fora ignorada na saudação a Noemi, quando da chegada das duas a Belém (1.9), até passar de mulher pobre a esposa de Boaz, para os grupos entre os quais ela transita, Rute segue não sendo "um deles". Ela é "Rute, a moabita" (4.10), "a mulher" (4.11), "esta jovem mulher" (4.12), "tua nora" (4.15).

\section{II}

O estrangeiro, na cultura antiga e moderna, é considerado um sujeito vulnerável, que reúne em si um conjunto de características negativas: ele é, por excelência, o estranho, aquele que pode se tornar uma ameaça, pelo menos no imaginário coletivo [...]. A sua estranheza decorre do idioma, da cultura, da religião, da maneira de se alimentar e se vestir etc. Por esses motivos, mais de natureza emotiva do que frutos de uma verdadeira reflexão, o estrangeiro é marginalizado, não é considerado "um dos nossos", portanto, deve ser "guetizado", não lhe são reconhecidos os direitos, com exceção de alguns, e é simplesmente tolerado [...] (SCAIOLA, 2007, p. 1).

\section{Soa familiar? Do conto ou da vida?}

Complexo em si mesmo, a migração é um fenômeno social que envolve análises igualmente complexas, multifocais e multidisciplinares que aqui não temos condições sequer de começar a esboçar adequadamente. Para ficar

15 Veja a discussão em DE VILLIERS; LE ROUX, 2016, p. 1-6. 
apenas em exemplos, elas passam pelo que os fluxos migratórios representam para países de origem, trânsito e destino em termos econômicos, políticos e culturais, por questões ligadas aos direitos humanos, adequação e/ou criação de políticas nacionais de migração (trabalho, saúde, educação, garantia de direitos etc.), discussões envolvendo assimetrias acentuadas por questões de gênero, discriminação étnico-racial e assim por diante.

Bienalmente, o Departamento de Assuntos Econômicos da Organização das Nações Unidas (ONU) divulga os números da migração internacional. O relatório de 2017 indica que aproximadamente 258 milhões de pessoas vivem em partes do globo que não são os seus países de origem ${ }^{16}$. Esses deslocamentos se dão de maneira voluntária ou forçada. O primeiro caso, entre outros aspectos, agrupa pessoas em busca de melhores condições de vida. O segundo reflete a situação de pessoas refugiadas, que se veem obrigadas a deixar a pátria devido a perseguição em função de raça, religião, nacionalidade, visão política, adesão a grupos sociais, conflitos armados, violência generalizada e violação dos direitos humanos. ${ }^{17}$

A despeito da motivação, muitos desses deslocamentos são irregulares. A Organização Internacional para as Migrações (OIM) alerta para o fato de que não existem estatísticas confiáveis sobre os números ou fluxos dessas migrações não autorizadas. O mesmo pode ser dito das informações sobre o bem-estar de pessoas nessa situação e do seu acesso a serviços como saúde e educação.

A irregularidade não se refere aos indivíduos, mas ao seu status migratório em um determinado momento. Mudanças nas leis e políticas nacionais podem transformar a migração regular em migração irregular e vice-versa. O status dos migrantes pode mudar durante sua jornada e permanência no país de trânsito/destino, o que dificulta ter uma visão abrangente da migração irregular e dos perfis dos migrantes irregulares. ${ }^{18}$

No contexto geral dos deslocamentos, o relatório sobre as migrações internacionais informa que, do total de migrantes apurado em 2017, aproximadamente 125 milhões (48,4\%) são mulheres. Suas motivações são diversas e apresentam variações em relação às migrações masculinas, sobretudo no que toca à violência em função do gênero, como no caso da violência sexual em áreas de conflito, com a disposição do corpo feminino como moeda na

16 United Nations, Department of Economic and Social Affairs, Population Division (2017). Trends in International Migrant Stock: The 2017 Revision. Disponível em: http://www.un.org/en/development/ desa/population/migration/data/estimates2/estimates17.shtml. Acesso em 04 jul. 2018.

17 Cf. a Convenção das Nações Unidas sobre o Estatuto dos Refugiados, de 1951, e informações complementares no site da Agência da ONU para Refugiados (http://www.acnur.org).

18 “Irregular migration". International Organization for Migration, Migration Data Portal. Disponível em https://migrationdataportal.org/themes/irregular-migration. Acesso em 04 jul. 2018. 
economia da guerra ${ }^{19}$. Para as mulheres, o escape de uma situação limite no local de origem, em especial no caso das migrações não autorizadas, não significa, no entanto, garantia de coisa alguma. Surge aí, acentuada, a contradição entre a liberdade e emancipação femininas (não compartilhadas por todas as sociedades, é bem verdade) e os abusos a que mulheres nessa condição se veem expostas, que podem variar da exploração financeira ou sexual na origem ou decurso do deslocamento até a servidão no destino final, com tudo o que pode ocorrer entre um ponto e outro (fome, dificuldade de acesso à saúde, discriminação étnico-racial, preconceitos de ordens diversas, violação dos direitos humanos básicos, tráfico humano etc.).

Os números da migração feminina deram origem ao que vem sendo chamado no campo de estudos correspondente de "feminização da migração", resultado direto de uma "feminização da pobreza" que decorre do aumento na diferença de níveis de pobreza entre mulheres e homens. E assim como a comida, também o deslocamento é lugar de uma profunda vulnerabilidade. Sem status político, a estrangeira (assim como o estrangeiro de um modo geral) não tem os mesmos direitos que os locais, sofre com a apatia oficial, submete-se a explorações da mão de obra, não raro do corpo, e não está contemplada pelas políticas públicas. É praticamente invisível.

\section{III}

Aqui voltamos a Rute. Sua leitura na perspectiva do estrangeiro pode lançar alguma luz sobre a reflexão acerca do mesmo tema no contexto contemporâneo. Por que uma pessoa, em especial uma mulher, quando não é forçada a isso, decide enfrentar situações que têm potencial para lhe violar virtualmente todos os direitos, submetê-la a circunstâncias degradantes e perigosas? Por que colocar-se na condição de "de fora", com tudo o que essa expressão significa na ciranda da negociação da identidade nacional com os "locais"? Ao propor uma leitura de Rute em paralelo com a situação de trabalhadoras migrantes no Israel contemporâneo, Athalya Brenner (2010, p. 167) arrisca um palpite: "a resposta só pode ser porque o que as espera em casa é muito, muito pior”.

E só pode ser. Tomemos como exemplo e objeto de reflexão para o momento o caso do recente fluxo imigratório venezuelano no Brasil, iniciado em 2015 e que as mídias informam aumentar diariamente na fronteira norte do país. Reportagens de diversos veículos reproduzidas site do Instituto

19 A esse respeito, veja o relatório do secretário geral da ONU sobre a violência sexual em áreas de conflito (2017), disponível em http://www.un.org/en/events/elimination-of-sexual-violence-in-conflict/pdf/1494280398.pdf. Acesso em 04 jul. 2018. 
Humanitas Unisinos/Adital (http://www.ihu.unisinos.br/) informam sobre a situação desses imigrantes em Roraima: sem o amparo de leis protetivas, o cotidiano é vivido no medo, em condições sub-humanas, com noites ao relento ou em abrigos lotados, sem condições apropriadas de higiene e água potável, com exploração sexual das mulheres em troca de comida e alojamento, exploração da mão de obra em troca de comida, surgimento de situações análogas à escravidão e assim por diante. Soma-se a isso a inabilidade do governo para lidar com as questões humanitárias decorrentes e a insatisfação dos locais. Ainda assim, parafraseando Brenner, um aspecto é recorrente na fala de entrevistados nessas reportagens: a situação de que buscavam escapar — a falta de comida - era (ou parecia ser) muito pior. No limite, a comida faz do imigrante um vulnerável não somente na saída do seu local de origem, mas especialmente no local de destino, como o caso dos venezuelanos em Roraima exemplifica, dando origem e margem a todo tipo de violência.

Outro aspecto são as dimensões subjetivas da identidade. Tendo em vista que a identidade é definida e reafirmada em relação ao contexto (identificação) e ao outro (alteridade) (MONTES, 1996), como se vê e se compreende a pessoa que se desloca? Ao mesmo tempo em que não pertence mais por completo à cultura de origem e que tem dificuldades para cultivá-la, o estrangeiro também pode não se integrar totalmente à cultura que o hospeda. Primeiramente existe a barreira da língua, e a ela se juntam outras, tais como a acentuação das próprias diferenças culturais, preconceitos, tendências à invisibilização no contexto social e político, a imposição da heteronormatividade etc. O estrangeiro é, nesse sentido, liminar e, como Rute, sua identidade social está em fluxo: ele é "o imigrante", "o de fora", "o invasor", "o intruso", "aquele que veio de"... Como a moabita, mesmo laborando arduamente numa terra estranha e nela construindo um percurso honrado, ele pode chegar ao final da própria narrativa ainda como "um deles" e não como "um dos nossos".

A comida é lugar de desmesurada vulnerabilidade. Também o é o deslocamento a que sua escassez obriga. Combinados, esses dois elementos testam de forma radical os limites das relações humanas. Como crítica à postura etnocêntrica, excludente e mesquinha em relação ao estrangeiro, Rute também funciona como metáfora do outro e modelo cultural de solidariedade. A sensibilidade e delicadeza com que a narrativa lida com problemas que espelham a vida como ela é abrem espaço para a reflexão sobre as condições objetivas cotidianas daquele que migra, bem como o impacto dessas condições no processo de construção da sua identidade social. Rute é, em última análise, um desafio sério a resistir à desumanização. 


\section{Referências bibliográficas}

AGÊNCIA DA ONU para Refugiados. Disponível em http://www.acnur.org. Acesso em 04 jul. 2018.

ASCHKENASY, Nehama. Reading Ruth through a bakhtinian lens: the carnivalesque in a biblical tale. Journal of Biblical Literature, Atlanta, vol. 126, n. 3, p. 437-453, 2007.

BECKING, Bob; WETTER, Anne-Mareike. Boaz in the Gate (Ruth 4,1-12): Legal Transaction or Religious Ritual? Zeitschrift für Altorientalische und Biblische Rechtsgeschichte, n. 19, p. 253-265, 2013.

BÍBLIA TRADUÇÃO ECUMÊNICA [TEB]. Nova edição revista e corrigida. São Paulo: Paulinas; Loyola, 1995.

BLEDSTEIN, Adrien J. Female companionships: if the Book of Ruth were written by a woman... In: BRENNER, Athalya (ed.). A feminist companion to Ruth. Sheffield: Sheffield Academic Press, 2001, p. 116-144.

BRAULIK, G. The Book of Ruth as intra-biblical critique on the Deuteronomic Law. Acta Theologica, Bloemfonteinn, vol. 19, n. 1, p. 1-20, 1999.

BRENNER, Athalya. From Ruth to the "Global Woman": social and legal aspects. Interpretation, v. 64, n. 2, p. 162-168, 2010.

CAMPBELL JR., Edward F. The Hebrew short story: a study of Ruth. In: BREAM, Howard N.; HEIM, Ralph D.; MOORE, Carey A. (ed.). A light unto my path: Old Testament Studies in Honor of Jacob M. Myers. Philadelphia: Temple University Press, 1974, p. 83101.

COOK, L. S. Reading Deuteronomy: a literary and theological commentary. Macon, GA: Smyt \& Helwys, 2015.

COUNIHAN, Carole; ESTERIK, Penny Van (ed.). Food and culture: a reader. 3. ed. New York; London: Routledge, 2013.

DE VILLIERS, G.; LE ROUX, J. The Book of Ruth in the time of the Judges and Ruth, the moabitess. Verbum et Ecclesia, v. 37, n. 1, p. 1-6, 2016.

DREHER, Carlos Arthur. Sexualidade e erotismo nas tradições patriarcais de Judá: o estranho caso das filhas de Ló (Gn 19.30-38). In: OLIVEIRA, Kathlen Luana de et al. (Org.). Religião, política, poder e cultura na América Latina. São Leopoldo: EST, 2012, p. 227-237.

DREHER, Martin Norberto. Memórias e narrativas nas religiões: o caráter literário do Antigo Testamento. Revista Brasileira de História das Religiões, vol. 5, n. 15, p. 217-226, jan. 2013. ECO, Umberto. Obra aberta. São Paulo: Perspectiva, 2013 (Col. Debates 4).

FEWELL, Danna Nolan (Ed.). The Oxford Handbook of Biblical Narrative. Oxford: Oxford University Press, 2016.

FEWELL, Danna Nolan; GUNN, David Miller. Compromising redemption: relating characters in the Book of Ruth. Eugene: Wipf and Stock, 2009.

FISCHER, Irmtraud. The Book of Ruth as exegetical literature. $38^{\text {th }}$ International JewishChristian Bible Week: The Book of Ruth. $23^{\text {rd }}-30^{\text {th }}$ July 2006.

FISCHER, Irmtraud. Rute: uma genealogia feminina. L'Osservatore Romano, 16 set. 2016. Disponível em http://www.osservatoreromano.va/pt/news/rute-uma-genealogia-feminina. Acesso em 04 jul. 2018. 
GITAY, Zefira. Ruth and the women of Betlehem. In: BRENNER, Athalya (Ed.). A feminist companion to Ruth. Sheffield: Sheffield Academic Press, 2001, p. 178-190.

GOETHE, Johann Wolfgang von. West-East Divan. The Poems with "Notes and Essays": Goethe's intercultural dialogues. Trad. Martin Bidney. Albany: State of New York University Press, 2010.

GOITEN, S. D. Women as creator of biblical genres. Prooftexts 8, p. 1-33, 1988.

GONÇALVES, Alfredo J. Casa, família e pátria no contexto da mobilidade urbana. REMHU - Revista Interdisciplinar da Mobilidade Humana, ano XVI, n. 30, p. 203-224, 2008.

GUNKEL, Hermann. What remains of the Old Testament and other essays. Eugene: Wipf and Stock Publishers, 2014.

HALTON, C. An indecent proposal: the theological core of the Book of Ruth. Scandinavian Journal of the Old Testament, vol. 26, n. 1, p. 30-43, 2012.

HOLZBERG, Niklas. The Ancient novel: an introduction. London; New York: Routledge, 2005.

HUBBARD JR., Robert L. The Book of Ruth. Grand Rapids: Eerdmans, 1988 (The New International Commentary on the Old Testament).

HUMPHREYS, W. L. Novella. In: COATS, G. W. (Ed.). Saga, legend, tale, novella, fable: narrative forms in Old Testament literature. Sheffield: Sheffield Academic Press, 1985 (JSOT. Sup. 35), p. 82-96.

INTERNATIONAL ORGANIZATION for Migration, Migration Data Portal. Disponível em https://migrationdataportal.org/themes/irregular-migration. Acesso em 04 jul. 2018.

JOHNSON, Sara. Third Macabees: historical fictions and the shaping of Jewish identity in the Hellenistic Period. In: BRANT, Jo-Ann A.; HEDRICK, Charles W.; SHEA, Chris (Ed.). Ancient fiction: the matrix of early Christian and Jewish narrative. Atlanta: Society of Biblical Literature, 2005, p. 185-197.

KRAEMER, R. S. Women's authorship of Jewish and Christian literature in the GrecoRoman Period. In: LEVINE, A.-J. (Ed.). “Women Like This”: new perspectives on Jewish women in the Greco-Roman World. Atlanta: Scholars Press, 1991 (Early Judaism and Its Literature 1), p. 221-242.

LaCOCQUE, A. Ruth. Minneapolis: Fortress Press, 2004.

LEFKOWITZ, M. R. Did ancient women write novels? In: LEVINE, A.-J. (Ed.). "Women Like This": new perspectives on Jewish women in the Greco-Roman World. Atlanta: Scholars Press, 1991 (Early Judaism and Its Literature 1), p. 199-219.

MARIANNO, Lilia Dias. Sogra e nora: parceiras? Viúvas e estrategistas sobrevivendo à fome (Rut). Ribla, n. 66, p. 115-127, 2010.

MATTHEWS, V. Judges and Ruth. Cambridge: Cambridge University Press, 2004.

MESTERS, Carlos. Rute. Petrópolis; São Paulo; São Leopoldo: Vozes; Imprensa Metodista; Sinodal, 1989.

MONTES, Maria Lúcia. Raça e identidade: entre o espelho, a invenção e a ideologia. In: SCHWARTZ, Lilia; QUEIROZ, Renato (Org.). Raça e diversidade. São Paulo: Editora da USP, 1996. 
PASCO, Allan H. On Defining Short Stories. New Literary History, vol. 22, n. 2, p. 407-422, 1991.

RELATÓRIO DO SECRETÁRIO geral da ONU sobre a violência sexual em áreas de conflito (2017). Disponível em http://www.un.org/en/events/elimination-of-sexual-violence-in-conflict/pdf/1494280398.pdf. Acesso em 04 jul. 2018.

SAXEGAARD, Kristin Moen. Character complexity in the Book of Ruth. Tübingen: Mohr Siebeck, 2010.

SCAIOLA, Donatella. Mulheres migrantes ou estrangeiras: re-intérpretes da fé de Israel. Centro Scalabriniano de Estudos Migratórios. 2007. Disponível em http://csem.org.br/pdfs/mulheres migrantes ou estrangeiras.pdf. Acesso em 04 jul. 2018.

TRIBLE, P. Book of Ruth. In: FREEDMAN, David Noel (Ed.). The Anchor Bible Dictionary. Vol. 5. New York: Doubleday, 1992, p. 842-847.

UNITED NATIONS, Department of Economic and Social Affairs, Population Division (2017). Trends in International Migrant Stock: The 2017 Revision. Disponível em: http://www. un.org/en/development/desa/population/migration/data/estimates2/estimates17.shtml. Acesso em 04 jul. 2018.

VILLIERS, Gerda de. Ecodomy: taking risks and overstepping boundaries in the Book of Ruth. Verbum et Ecclesia, vol. 38, n. 3 (sup. 1), p. 35-50, 2017.

WETTER, Anne-Mareike. "On Her Account": reconfiguring Israel in Ruth, Esther and Judith. London: Bloomsburg, 1998.

WILLS, Lawrence M. (Ed.). Ancient Jewish novels: an anthology. Oxford: Oxford University Press, 2002.

WILLS, Lawrence M. The Jewish novel in the ancient world. Ithaca; London: Cornell University Press, 1995.

WUENCH, Hans-Georg. The stranger in God's land - Foreigner, stranger, guest: What can we learn from Israel's attitude towards strangers? Old Testament Essays, vol. 27, n. 3, p. 1129-1154, 2014.

Submetido em: 11-3-2019

Aceito em: 11-6-2019 